\title{
Effect of positioning on the breathing pattern of preterm infants
}

\author{
Ruth Heimler, Jeanne Langlois, Daniel J Hodel, Leif D Nelin, P Sasidharan
}

\begin{abstract}
Respiration, as judged by gas exchange and pulmonary function, is improved in preterm infants kept in the prone rather than the supine position. The influence of position on the breathing pattern as documented by the pneumogram was studied in 14 stable preterm infants with recent clinical apnoea. Ten of the infants had oximetry and nasal flow studies simultaneously with the impedance pneumogram. Each infant had consecutive nocturnal pneumograms, one in the prone, one in the supine position. The infants were kept for more than six hours in the assigned position.

A significant increase in apnoea density and in periodic breathing was found in the supine $v$ the prone position (mean (SE) $4.5(0.7) \% v$ $2.5(0.5) \%$, and $13.6(3.2) \%$ v $7.7(2.2) \%$, respectively). There was no positional difference in the incidence of bradycardia and prolonged apnoea. The examination of obstructive apnoea, mixed apnoea, and cyanotic spells did not reveal a consistent disparity between the two positions.

These findings indicate an increase in central apnoea in preterm infants kept predominantly in the supine position. Possible relations of positional changes to lung mechanics are discussed. When evaluating pneumograms, attention must be given to the position in which they were performed.
\end{abstract}

Clinical experience suggests that preterm infants breathe better when kept prone. Several investigators have shown that gas exchange as evidenced by arterial tension of oxygen and carbon dioxide $\left(\mathrm{PaO}_{2}\right.$, and $\left.\mathrm{PaCO}_{2}\right)$, is better in the prone than in the supine position,,$^{1-3}$ and pulmonary function tests improve when preterm infants are changed from lying supine to prone. $^{34}$ Kravitz et al found an increase in respiratory rate in the prone versus the supine position in preterm infants. ${ }^{5}$ This study was undertaken to examine the influence of position on the breathing pattern, as documented by the pneumogram, in preterm infants who had recent apnoea and bradycardia, with the assumption that all types of apnoea would be increased in the supine position.

\section{Methods}

Fourteen preterm infants (gestational age mean (SD) $29 \cdot 7(2 \cdot 8)$ weeks, range 26-36 weeks, and birth weight mean (SD) 1381 (474) g, range $840-2290 \mathrm{~g}$ ) who had recent clinical apnoea but were otherwise healthy were enrolled in the study, after informed consent was obtained from the parents. Nine infants had previous respiratory distress syndrome requiring up to eight days of intubation. Infants with bronchopulmonary dysplasia were excluded from the study. The infants did not require respiratory support or oxygen, and were all enterally fed (bolus feedings either by nipple or by intermittent gavage) at the time of the study. Eight infants received maintenance methylxanthine therapy and had stable therapeutic blood concentrations.

The breathing pattern was studied by the cardiorespirogram (pneumogram). Each infant had consecutive nocturnal 12 hour impedance pneumograms: one while in the prone and one in the supine position. The order was assigned at random, by sealed envelopes. When assigned to the prone position, infants were kept in the assigned position all night, except during feeding. When assigned to the supine position, infants were kept supine except for one hour after feeding, when they were placed prone to facilitate burping and prevent aspiration. The infants spent the majority of the study period in the assigned position. No attempt was made to keep the head in midline position. In general, the head was turned to the side $75-90^{\circ}$ when prone and about $45^{\circ}$ when supine. The infant's neck and shoulders were supported to avoid neck flexion.

Pneumograms were analysed using a Pediatric Diagnostic Service computer program, as developed by Kelly et al. ${ }^{6}$ Apnoea episodes were defined as cessation of breathing for $\geqslant 6$ seconds. Apnoea density $\left(\mathrm{AD}_{6}\right)$ was defined as the percentage of apnoea time while the infant was quite $\left(\mathrm{AD}_{6}=100 \times\right.$ seconds of apnoea/seconds of quiet state). The infant was considered to be quiet when heart rate and respiratory pattern were stable, without artefacts. Bradycardia was defined as a decrease in heart rate below 100 beats/minute for $\geqslant 5$ seconds. Periodic breathing was defined as three episodes of apnoea $\geqslant 3$ seconds interrupted by respiration lasting $\leqslant 20$ seconds.

Central apnoea was defined as a cessation of both breathing movements and nasal airflow. Obstructive apnoea was defined as a cessation of nasal flow while breathing movements continued with a fall in oxygen saturation lasting $\geqslant 5$ seconds. Mixed apnoea spells were defined as obstructive breaths combined with irregular breathing movements. The latter were usually of longer duration along with a significant drop in oxygen saturation. Desaturation was defined as a drop in oxygen saturation to $<87 \cdot 5 \%$, lasting $\geqslant 10$ seconds. 
Obstructive and mixed apnoea was examined in 10 of the 14 infants by recordings of nasal flow and oximetry, obtained simultaneously with the impedance pneumogram. Nasal air flow was measured by end tidal carbon dioxide (Engstrom Eliza carbon dioxide analyzer, Astro Med); oximetry was measured by a Nellcor pulse oximeter. These parameters, as well as heart rate, breathing movements, and heart rate off the oximeter, were recorded on a multichannel recorder. Obstructive or mixed apnoea periods of $\geqslant 6$ seconds' duration and oxygen desaturation episodes were counted manually by one of the investigators (JL), who was blinded regarding the position during the recordings. Episodes of generalised body movements as evidenced by abrupt changes and irregularities in heart rate, or drops in heart rate on the oximeter not concurring with bradycardia, were excluded from the analysis.

Results were shown as mean (SE). To compare the prone with the supine position the Student's $t$ test for paired samples was used and differences were considered significant when $\mathrm{p}<0.05$.

\section{Results}

Fourteen infants were studied at mean (SD) 34.4 (1.9) weeks (range 32-36 weeks) postconceptional age. The infants age at the time of study ranged between 1 and $8 \cdot 5$ weeks (weight

Table 1 Impedance pneumogram analysis $(n=14)$. Values are shown as mean (SE)

\begin{tabular}{|c|c|c|c|c|}
\hline & Supine & Prone & $\begin{array}{l}\text { Mean } \\
\text { difference } \\
\text { supine-prone }\end{array}$ & p Value \\
\hline $\begin{array}{l}\text { Apnoea episodes } * 6 \mathrm{~s} \\
\text { Apnoea episodes } 11-15 \mathrm{~s} \\
\text { Apnoea episodes } \geqslant 15 \mathrm{~s} \\
\text { Apnoea in non-periodic breathing (s) } \\
\text { Apnoea in periodic breathing }(\mathrm{s}) \\
\text { All apnoea (s) } \\
\text { Bradycardia episodes } \\
\text { AD total } \\
\text { Periodic breathing (\% of quiet) } \\
\text { Quiet time (min) }\end{array}$ & $\begin{array}{ll}175 \cdot 5 & (28 \cdot 5) \\
4 \cdot 6 & (1 \cdot 3) \\
2 \cdot 3 & (1 \cdot 0) \\
487 & (56) \\
840 & (190) \\
1327 & (210) \\
3 \cdot 4 & (1 \cdot 0) \\
4 \cdot 5 & (0 \cdot 7) \\
13 \cdot 6 & (3 \cdot 2) \\
501 & (20)\end{array}$ & $\begin{array}{ll}110 \cdot 3(22 \cdot 2) \\
2 \cdot 4 & (0 \cdot 9) \\
0 \cdot 4 & (0 \cdot 2) \\
364 & (47) \\
451 & (140) \\
815 & (162) \\
3 \cdot 8 & (1 \cdot 5) \\
2 \cdot 5 & (0 \cdot 5) \\
7 \cdot 7 & (2 \cdot 2) \\
522 & (23)\end{array}$ & $\begin{array}{ll}65 \cdot 2 & (20 \cdot 9) \\
2 \cdot 2 & (0 \cdot 9) \\
1 \cdot 9 & (1 \cdot 0) \\
123 & (58) \\
389 & (145) \\
512 & (163) \\
-0 \cdot 4 & (0 \cdot 8) \\
2 \cdot 0 & (0 \cdot 6) \\
5 \cdot 9 & (2 \cdot 1) \\
-21 & (22)\end{array}$ & $\begin{array}{l}0.008 \\
0.032 \\
0.074 \\
0.05 \\
0.018 \\
0.008 \\
0.65 \\
0.01 \\
0.015 \\
0.40\end{array}$ \\
\hline
\end{tabular}

${ }^{*}$ Episodes are shown as number/recording.

$\mathrm{AD}_{6}$ (Apnoea density) is apnoea episodes $\geqslant 6$ seconds expressed as the percentage of quiet time.

Table 2 Effect of feeding on the postprandial impedance pneumogram $(n=14)$. Values are shown as mean ( $S E)$

\begin{tabular}{llllllll}
\hline & $\begin{array}{l}\text { Supine } \\
\text { group }\end{array}$ & $\begin{array}{l}\text { Prone } \\
\text { group }\end{array}$ & $\begin{array}{l}\text { Mean } \\
\text { difference } \\
\text { supine-prone }\end{array}$ & p Value \\
\hline Apnoea in non-periodic breathing (s) & 213 & $(39)$ & 116 & $(17)$ & 97 & $(35)$ & 0.015 \\
Apnoea in periodic breathing (s) & 240 & $(70)$ & 62 & $(21)$ & 178 & $(63)$ & 0.014 \\
All apnoea (s) & 453 & $(100)$ & 186 & $(37)$ & 267 & $(88)$ & 0.01 \\
Apnoea episodes $\geqslant 11 \mathrm{~s}$ & 4.3 & $(1 \cdot 7)$ & 0.9 & $(0.4)$ & 3.4 & $(1 \cdot 4)$ & 0.031 \\
\hline
\end{tabular}

Table 3 Duration of spells of obstructive or mixed apnoea and of desaturation in seconds during a 12 hour period and during feeding and postprandial periods $(n=10)$. Values are shown as mean (SE)

\begin{tabular}{|c|c|c|c|c|c|c|c|}
\hline \multirow{3}{*}{$\begin{array}{l}\text { All mixed apnoea } \\
\text { All obstructive apnoea } \\
\text { All desaturation } \\
\text { Feeding and postprandial period } \\
\text { Mixed apnoea } \\
\text { Obstructive apnoea } \\
\text { Desaturation }\end{array}$} & \multirow{2}{*}{\multicolumn{2}{|c|}{$\begin{array}{ll} & \text { Supine } \\
& \\
137 & (57) \\
703 & (146) \\
330 & (95)\end{array}$}} & \multicolumn{2}{|c|}{ Prone } & \multicolumn{2}{|c|}{$\begin{array}{l}\text { Mean } \\
\text { difference } \\
\text { supine-prone }\end{array}$} & \multirow{2}{*}{$\begin{array}{l}\text { p Value } \\
\\
0.50 \\
0 \cdot 45 \\
0.50\end{array}$} \\
\hline & & & $\begin{array}{r}95 \\
615 \\
277\end{array}$ & $\begin{array}{l}(25) \\
(86) \\
(65)\end{array}$ & $\begin{array}{l}42 \\
88 \\
53\end{array}$ & $\begin{array}{l}(51) \\
(108) \\
(79)\end{array}$ & \\
\hline & $\begin{array}{r}66 \\
225 \\
180\end{array}$ & $\begin{array}{l}(23) \\
(63) \\
(75)\end{array}$ & $\begin{array}{r}43 \\
258 \\
167\end{array}$ & $\begin{array}{l}(14) \\
(66) \\
(48)\end{array}$ & $\begin{array}{l}23 \\
33 \\
13\end{array}$ & $\begin{array}{l}(22) \\
(33) \\
(78)\end{array}$ & $\begin{array}{l}0 \cdot 45 \\
0 \cdot 30 \\
0 \cdot 87\end{array}$ \\
\hline
\end{tabular}

${ }^{*}$ Desaturation is oxygen saturation of $<87 \cdot 5 \%$, lasting $\geqslant 10$ seconds. range $1270-2250 \mathrm{~g})$. More mature infants were studied at an earlier age.

Table 1 describes the differences in the impedance pneumogram. There was a significant increase of apnoea density in the supine versus the prone position $(p=0.01)$. Supine positioning resulted in a $77 \%$ increase in periodic breathing $(p=0.015)$. There was no positional difference in respiratory rate or in heart rate.

The mean (SD) number of feeds per infant was $4(1 \cdot 1)$ during the 12 hour recordings. Table 2 shows the effect of bolus feedings on the pneumogram, as seen one hour postprandially. There was a significant increase in postprandial apnoea during the night the infants were nursed supine compared with the night they were nursed prone. The increase in apnoea was as pronounced in non-periodic breathing as in periodic breathing $(\mathrm{p}=0.015)$.

No large or consistent positional difference was demonstrated in the duration of spells of obstructive or mixed apnoea nor in the duration of oxygen desaturation episodes in the 10 infants examined (table 3 ).

\section{Discussion}

This study demonstrates an increase in the incidence of apnoea in the supine compared with the prone position. The positional difference existed both during periods of non-periodic breathing as well as during periods of periodic breathing. The increase in apnoea while in the supine position presented as an increase in central apnoea as demonstrated by the $\mathrm{AD}_{6}$ total. The positional difference in the impedance pneumogram is not secondary to the order in which the pneumograms were obtained nor to interval improvement in apnoea because the order of the study positions was random. Moreover, another study did not find a significant difference between consecutive pneumograms in a large number of patients. ${ }^{7}$

The mechanism of the increase in central apnoea demonstrated in the supine position is not entirely clear. Respiration in the preterm infant is regulated by mechanoreceptors mediated via vagal fibres (the Hering-Breuer reflex), peripheral and central chemoreceptors, and a suprapontine respiratory centre. ${ }^{8}$ Preterm infants, while in active sleep, exhibit asynchronous movements of the intercostal muscles in relation to diaphragmatic contraction. The resulting rib cage distortion may cause a decrease in functional residual capacity and in pulmonary oxygen reserve. ${ }^{8}$ This would render the higher respiratory centre more prone to hypoxia, leading to respiratory depression and apnoea. Martin et al have found a very significant increase of asynchronous breathing coupled with decreased oxygenation in the supine compared with the prone position. ${ }^{1}$ A compensatory increase of diaphragmatic movements during asynchronous breathing may also lead to increased diaphragmatic fatigue. ${ }^{89}$ Prone positioning allows the posterior portion of the diaphragm, which has a lesser curvature and more effective respiratory movements, to function unopposed by abdominal pressure. 310 Diaphragmatic fatigue, which has been observed 
in relation to clinical apnoea, ${ }^{11} 12$ may thus be more pronounced in the supine position.

The postprandial comparison of the two positions could be further evidence of the role of diaphragmatic fatigue. Feeding preterm infants has been shown to decrease lung volume, ${ }^{13}$ and to increase diaphragmatic work. ${ }^{14}$ When the infants were studied in the supine position they were prone for one hour postprandially. However, comparing the postprandial hour between the two positions reveals more apnoea in the infants who were supine before feeding. This suggests that the supine position compromises diaphragmatic function so that a further work load, as seen with feedings, is not well tolerated. This would then lead to an increase in apnoea.

The finding that the increase in apnoea in the supine position presented primarily as the central type was surprising. A study comparing the supine with the sitting position in infants demonstrated an increase in airway resistance when supine, especially when the neck was flexed. ${ }^{15}$ The pneumogram study of Miller $e t$ al of babies in the supine position revealed that about half of the apnoea episodes were obstructive or mixed, and could be abolished by continuous positive airway pressure. ${ }^{16}$ Our finding that apnoea spells of an obstructive nature were not consistently increased when supine may be due to our strict avoidance of neck flexion in this position. A contribution of increased gastro-oesophageal reflux to the apnoea spells while supine is also unlikely, as the increase in spells was largely of the central type.

A tendency for an increase in airway resistance below the neck in the supine position compared with the prone in intubated preterm infants was found by Wagaman et al. ${ }^{3}$ We do not know whether this, too, might contribute to diaphragmatic fatigue presenting with central apnoea, as indeed nine of the smaller infants in the present study had previous respiratory distress syndrome, albeit without consequential chronic lung disease. In contrast to previous studies, ${ }^{1-4}$ we did not find a positional difference in episodes of oxygen desaturation in the 10 infants studied. This does, however, concur with the lack of positional difference in prolonged apnoea and bradycardia spells in our patients.

In conclusion, we have demonstrated an increase in central apnoea in preterm infants with clinical apnoea cared for predominantly in the supine position compared with the prone position. As there was no positional difference in prolonged apnoea or bradycardia spells, the clinical implication of our results is uncertain, although the increase in periodic breathing in the supine position deserves attention. The main significance of this study resides in the finding of disadvantage of the supine versus the prone position, which is in agreement with the observations during gas exchange and pulmonary function tests. ${ }^{1-4}$ We speculate that decreased lung volume and increased diaphragmatic work when supine are important in the genesis of the positional difference in apnoea density. There is a need for further studies correlating positional pneumograms with pulmonary function and diaphragmatic mechanics. Finally, when evaluating pneumograms, the position of the infant during the major part of the study must be known.

This study was supported in part by Physiologic Diagnostic Services, Inc.

We thank Professor RDG Milner for reviewing this manuscript and for the helpful suggestions.

1 Martin RJ, Herell N, Rubin D, Fanaroff A. Effect of supine and prone positions on arterial oxygen tension in the and prone positions on arterial oxygen tens

2 Lioy J, Manginello FP. A comparison of prone and supine positioning in the immediate post-extubation period of positioning in the immediate post-exty

3 Wagaman MJ, Shutack DO, Moomjian AS, et al. Improved lung oxygenation and lung compliance with prone positioning of neonates. $\mathcal{f}$ Pediatr 1979;94:787-91.

4 Hutchinson AA, Ross KR, Russell G. The effect of posture on ventilation and lung mechanics in preterm and light-fordate infants. Pediatrics 1979;64:429-32.

5 Kravitz $H$, Elegant $L$, Block B, et al. The effect of position on the respiratory rate of premature and mature newborn infants. Pediatrics 1958;22:432-5.

6 Kelly DH, Golub H, Shannon DC. Computer analysis of pneumograms. Am Rev Respir Dis 1984;129:208.

7 Hunt CE, Brouillette RT, Liu K, et al. Day-to-day pneumogram variability. Pediatr Res 1985;19:174-7.

8 Martin RJ, Miller MJ, Carlo WA. Pathogenesis of apnea in preterm infants. $\mathcal{F}$ Pediatr 1986;109:733-41.

9 Bryan MH. The work of breathing during sleep in newborns. Am Rev Respir Dis 1979;119:137-8.

10 Bryan AC. Comments of a devil's advocate. Am Rev Respir Dis 1974;110:143-4.

11 Heldt GP. Development of stability of the respiratory system in preterm infants. F Appl Physiol 1988;65:441-4.

2 Muller N, Gulston G, Cade D, et al. Diaphragmatic muscle fatigue in the newborn. F Appl Physiol 1979;46:688-95.

13 Pitcher-Wilmott R, Shutack JG, Fox WW. Decreased lung volume after nasogastric feeding of neonates recovering from respiratory disease. $\mathcal{F}$ Pediatr 1979;95:119-21.

14 Heldt GP. The effect of gavage feeding on the mechanics of the lung, chest wall, and diaphragm of preterm infants. Pediatr Res 1988;24:55-8.

15 Carlo WA, Beoglos A, Siver BS, Martin RJ. Neck and body position effects on pulmonary mechanics in infants. Pediatrics 1989;84:670-4.

16 Miller J, Carlo WA, Martin RJ. Continuous positive airway pressure selectively reduces obstructive apnea in preterm infants. F Pediatr 1985;106:91-4. 